\section{Impacts of acute exposure of industrial chemicals and pesticides on the survival of fish (Tilapia guineensis) and earthworms (Aporrectodea longa)}

Doris F. Ogeleka, ${ }^{1}$

Emmanuel T. Ogbomida, ${ }^{2}$ Isioma Tongo, ${ }^{3}$

Alex A. Enuneku, ${ }^{3}$ Thomas O. Ikpesu, ${ }^{4}$

Lawrence I.N. Ezemonye ${ }^{3}$

'Department of Chemistry, Federal

University of Petroleum Resources, Effurun, Delta State; ${ }^{2}$ Ecotoxicology and Environmental Forensics Unit, National Centre for Energy and Environment, Energy Commission of Nigeria, University of Benin, Benin City; ${ }^{3}$ Department of Animal and Environmental Biology (AEB), Faculty of Life Sciences, University of Benin, Benin City, Edo State; ${ }^{4}$ Department of Environmental Sciences, Federal University, Otuoke, Bayelsa State, Nigeria

\section{Abstract}

Ecotoxicological effects of industrial chemicals (Rig wash, Oil eater, Nalco, Glycol ${ }^{\mathrm{TM}}$ ) and pesticides (Propoxur, Deltamethrin, Atrazine, Furadan) on Tilapia guineensis (fish) and Aporrectodea longa (earthworms) were tested using the Organisation for Economic Cooperation and Development (OECD) \# 203 and 207 protocols. The water and soil ratings indicate that the test chemicals were toxic to the organisms. The estimated 96 hour lethal concentration $\mathrm{LC}_{50}$ values for Rig wash, Oil eater, Nalco EC1304A/COT 505, Glycol, Propoxur, and Deltamethrin were $26.34 \pm 0.46$, $6.02 \pm 0.30,3.07 \pm 0.14,1.31 \pm 0.01,20.91 \pm 0$ and $0.01 \pm 0 \mathrm{mg} / \mathrm{l}$ respectively. In the earthworm bioassay, the estimated 14-day $\mathrm{LC}_{50}$ values for Rigwash, Oil eater, Nalco EC1304A/COT 505, Glycol, Atrazine and Furadan were $80.05 \pm 3.5$, $151.55 \pm 10.7,172.63 \pm 14.2,63.72 \pm 2.43,4.97 \pm 0$ and $0.29 \pm 0 \mathrm{mg} / \mathrm{kg}$ respectively. Safety factors are arbitrarily built in around the $\mathrm{LC}_{50}$ values in order to arrive at environmentally tolerable concentrations. The concentration of a chemical in the receiving environment should not exceed $10 \%$ of the $\mathrm{LC}_{50}$. The organisms exposed to the test chemicals showed significant difference when compared with the levels measured in the control group. The observed sensitivity of the test organisms to the chemicals indicates that adherence to standard safety limits/measures should be maintained dur- ing use and disposal of hazardous chemicals. This would ensure that the biotic components of the Nigerian Niger Delta ecosystem are prudently protected.

\section{Introduction}

Over the past century humans have introduced a large number of chemical substances into the environment. Obviously some of these chemicals are useful but many are toxic and their harm to the environment and our health far outweighs their benefit. Man-made chemicals such as demulsifiers, dispersants, corrosion inhibitors and pesticides contaminate land and water and may adversely affect terrestrial and aquatic biota. These chemicals are released into the environment through usage, spillage, transportation, disposal and unintentionally. Chemoreceptors of aquatic organisms have been known to be destroyed by toxic organics, thereby affecting their mating and reproduction process. There is growing scientific consensus that numerous industrial and agricultural chemicals have the ability to interfere with endocrine systems and hormonal activities of all animals. Many wildlife species are exposed to biologically active concentrations of endocrine-disrupting chemicals. For example, a greater number of the world's amphibian species about $32 \%$ are threatened with extinction, $43 \%$ experiencing declines and another $22 \%$ with insufficient data ${ }^{1,2}$ due to impaired reproduction and development causally linked to endocrine-disrupting chemicals. A well-documented evidence of masculinization (imposex) in periwinkle snails by tributyltin, a biocide used in antifouling paints ${ }^{3}$ and demasculinization and feminization of amphibians by atrazine ${ }^{4}$ have also be reported. All these could subsequently lead to reduction as well as extinction of some vital species. ${ }^{5-9}$

Industrial chemicals (demulsifiers, corrosion inhibitors and dispersants) mainly of surfactant-based commonly used by industrial petroleum operators may cause environmental problems including the toxicity of the surfactants to fish and invertebrates, foaming and euthrophication. ${ }^{10,11} \mathrm{~A}$ foaming agent is a material that facilitates formation of foam such as a surfactant. A surfactant, when present in small amounts, reduces surface tension of a liquid (reduces the work needed to create the foam) or increases its colloidal stability by inhibiting coalescence of bubbles. Detergents that contain phosphate are highly caustic, and surfactant detergents are very toxic. They are widely used in daily activities and these detergents cause excess frothing and growth of floating aquatic weeds (eutrophication) on the water surface, affecting aeration and quality of fresh water and adversely affects the physio-
Correspondence: Emmanuel T. Ogbomida,

Ecotoxicology and Environmental Forensics Unit, National Centre for Energy and Environment (NCEE), Energy Commission of Nigeria (ECN), University of Benin, Benin City, Nigeria.

Tel.: +234.80.33862226.

E-mail: 0gbomida.e@ncee.org.ng

Key words: Toxicity; fish; earthworm; demulsifier; corrosion inhibitor; safety limit; pesticides.

Acknowledgements: this study was supported by the National Centre for Energy and Environment (NCEE) (Energy Commission of Nigeria, ECN) University of Benin, Benin City, Research Grant. The contribution of every member of the thematic group is acknowledged.

Received for publication: 2 December 2015. Revision received: 26 August 2016. Accepted for publication: 26 August 2016.

This work is licensed under a Creative Commons Attribution NonCommercial 4.0 License (CC BYNC 4.0).

(O) Copyright D.F. Ogeleka et al., 2016

Licensee PAGEPress, Italy

Journal of Xenobiotics 2016; 6:5660

doi:10.4081/xeno.2016.5660

logical and biochemical processes of fish. Similarly, pesticides present the only group of substances of chemical or biological origin that are purposely applied to the environment with aim to suppress plant and animal pests as well as to protect agricultural and industrial products. However, over $98 \%$ of sprayed pesticide reach a destination other than their target species, including non-target species, air, water, bottom sediments, and soil. ${ }^{12}$ Repeated application could lead to loss of biodiversity since they usually act by disrupting some component of the pest's life processes to kill or inactivate it. ${ }^{13}$ Most of these chemicals especially pesticides are not easily degradable, they persist in soil, leach to groundwater, surface water and contaminate the environment. Depending on their chemical properties, synthetic pesticides can enter an organism, bioaccumulate in food chains and consequently influence human health. ${ }^{14}$ Thus, the overall intensive pesticide application results in several negative effects in the environment that cannot be ignored. ${ }^{15}$

Presently in Nigeria, only a few chemicals have been ecologically tested for their safety in spite of their ecological and environment impact. Although the Federal Government of Nigeria is currently emphasizing the need for adequate environmental protection by strictly asking industrial operators to adequately characterise any chemical used in their operation before subsequent disposal into the environment. ${ }^{16,17}$ Retardation in growth and total anni- 
hilation of life could occur if these chemicals are discharged indiscriminately into the environment, hence the regulators in Nigeria; Department of Petroleum Resources (DPR) and Federal Ministry of Environment (FME) enforces laws guiding the disposal of these chemicals. However, apart from the direct effect, these chemicals can reduce the availability of food for man's consumption. , $^{9,10,18}$

The objective of this study was to evaluate the acute effects of four chemicals (Rigwash, Oil eater, Nalco EC1304A/COT 505, Glycol ${ }^{\mathrm{TM}}$ ) and four pesticides (Propoxur, Deltamethrin, Atrazine, Furadan) using fish (Tilapia guineensis) and earthworm (Aporrectodea longa) with a view to determining their safe limits. The industrial chemicals were assessed due to their indiscriminate use in oil spill clean-up in Niger Delta waters. Similarly, the pesticides were tested because they are the major pesticides used in Nigeria to control a number of pests on food crops such as grains, tea, fruits and vegetable crops and on non-food crops such as tobacco and cotton. ${ }^{19}$ Fish and earthworm were used to represent the health of aquatic and terrestrial ecosystems.

\section{Materials and Methods}

\section{Test chemicals}

The test chemicals namely, Rig wash, Oil eater, Nalco EC1304A/COT 505, Glycol ${ }^{\mathrm{TM}}$, Propoxur, Deltamethrin, Atrazine and Furadan were obtained from their respective manufacturers. The selected chemicals are widely used in agriculture and oil industries around the world. Active ingredients were used instead of commercial formulations, aiming to document the acute effects of the active substances on the mortality rather than the effects of adjuvants added in the commercial products. Ethylene glycol, a versatile organic compound that, moderately viscous, hygroscopic liquid at room temperature is manufactured by Huntsman Chemicals. Rigwash a special aqueous blend of anionic and non-ionic surfactant is produced by Global Drilling Fluids and Chemicals Limited in Gujarat, India. It is one of the most Popular Clean up Chemicals for the Oilfield Industry. It is an excellent emulsifier and may be used at any point in the drilling operation to improve emulsification and reduce torque and drag. It is highly effective in both fresh water and seawater. Oil Eater is ultra concentrated, biocatalytic multi-enzyme liquid concentrate. It is biodegradable and non-flammable and when combined with fresh or salt water and oxygen, it causes crude oil and other organic substances to rapidly decompose, eventually biodegrading them to carbon dioxide and water. It also safely dissolves grease and oils from asphalt and concrete. Oil
Eater is perfect for pressure washing, parts cleaning, mopping and floor cleaning. It is produced by Kafko International Ltd. Nalco EC1304A/COT 505 condensate corrosion inhibitor provides a full complement of volatile, filming and blended corrosion inhibitors to help arrest condensate corrosion. It addresses water conditions related to hardness, oxygen, silica, iron and more. It is manufactured by Nalco Chemical Company, a corporation of Delaware, USA.

Propoxur is a non-systemic carbamate insecticide widely used to kill all pests' in house and public area, such as cockroaches, mosquitoes, flies, ants, fleas, louses, bedbugs, etc. It is especially effective on rice leafhoppers and plant hoppers. It blocks the production and action of cholinesterase, an essential nervous system enzyme, quickly paralyzes the nervous systems of those insects. It is produced by Shanghai Kima Chemical Company Ltd. Atrazine is a selective systemic herbicide used on pre- and post-emergence control of annual broad-leaved weeds and annual grasses in maize, sorghum, sugar cane, pineapples, chemical fallow, grassland, macadamia nuts, conifers, industrial weed control. It is manufactured by Syngenta Corporation. Carbofuran is one of the most toxic carbamate pesticides. It is marketed under the trade names Furadan. Furadan is a systemic insecticide used to control insects in a wide variety of field crops, including potatoes, corn and soybeans. It is manufactured by FMC Corporation. Deltamethrin is a pyrethroid insecticide that kills insects on contact and through digestion. It is used to control apple and pear suckers, plum fruit moth, caterpillars on brassicas, pea moth, aphids (apples, plums, hops), winter moth (apples and plums), codling and tortrix moths (apples). It is manufactured by Sumitomo Chemical Co. Ltd (Japan).

\section{Test organisms}

\section{Fish (Tilapia guineensis)}

Tilapia guineensis (fish) from fresh water environment were collected from a cultured farm in Ekrheranwhen in the Niger Delta ecological zone of Nigeria. Ekrheranwhen is located in Ughelli North Local Government Area of Delta State, Nigeria (latitude $05^{\circ} 32$ ' $43.6^{\prime \prime} \mathrm{N}$ and longitude $\left.005^{\circ} 55^{\prime} 04.6^{\prime \prime} \mathrm{E}\right)$. The test organisms were acclimated to laboratory conditions for seven days in large holding tanks before the experiment. The acute toxicity was determined in terms of $96-\mathrm{hr} \mathrm{LC}_{50}$ and lethal concentrations according to the OECD Guideline \# 203 protocol for Testing of Chemicals 210, Fish, Early Life Stage Toxicity Test. $^{20}$

\section{Earthworms (Aporrectodea longa)}

The Oligochaete Aporrectodea longa is currently used invertebrate species for ecotoxico- logical assessment of substances in soil, which is the OECD and International Standardization Organization (ISO) recommended earthworms test species. ${ }^{21-23}$ Adult earthworms (weighing between 400-600 mg) with well-developed clitella were collected by gentle digging and hand sorting from sub surface litters from the Plant and Animal Biotechnology Garden at the Faculty of Life Sciences University of Benin, Nigeria and cultured in the laboratory in artificial soil according to OECD guidelines. ${ }^{21,22}$ The acute toxicity of earthworm exposed to the test chemicals was determined using the OECD \# 207 protocol. ${ }^{21}$ The soil samples were prepared by mixing clean dry soil with $5 \mathrm{~g}$ of cellulose and $80 \mathrm{ml}$ (test solution) homogenized in a glass container. Soil water content was measured every week and moisture was adjusted to $35 \%$ of the maximum water-holding capacity by adding distilled water whenever necessary. Thereafter, ten voided earthworms (400-600 $\mathrm{mg}$ ) were cleaned and transferred from their holding containers with a sterilized platinum wire to the soils spiked with concentrations of the test chemicals in three replicates. The control experiment contained ten (10) organisms, cellulose, water and clean soil. ${ }^{24}$

\section{Experimental design}

The semi-static renewal bioassay procedure started with a range finding test. This was used to determine the range of concentrations for the definitive test. The test concentrations for the definitive test were prepared by appropriate dilution of the stock solutions. Five different concentrations of the test industrial chemicals were prepared by dissolving in $5 \mathrm{ml}$ of deionised water in geometric series of $31.25,62.5,125,250$, and $500 \mathrm{mg} / \mathrm{l}$ while four different concentrations of $2.5,5,10$ and $15 \mathrm{mg} / \mathrm{l}$ for pesticides were also prepared. A total of five (5) litres of the test medium and control (dilution water) was used to test 10 test organisms in three replicates. ${ }^{20}$ After approximately 24 hours, the test solutions were renewed and their physico-chemical constituents namely $\mathrm{pH}$, temperature, total dissolved solids (TDS), salinity and conductivity were measured at test initiation and termination. The organisms were not fed during the 96 $\mathrm{h}$ experimental period. The weight and length of the fish were $0.471 \pm 0.03 \mathrm{~g}$ and $1.83 \pm 0.12$ $\mathrm{cm}$ respectively (Table 1 ).

Two replicates were made for each treatment. Aporrectodea longa were segregated from the culture beds, washed with deionised water and kept in a trough on moist filter paper for three hours to devoid their gut contents. These worms were rinsed again with deionised water, blotted on a filter paper and placed one in each Petri plate. Each Petri plate was covered with a perforated plastic film. Test Petri plates were kept at laboratory temperature of $20 \pm 2^{\circ} \mathrm{C}$ for 48 hours and worm's mortal- 
ity was observed by giving a gentle mechanical stimulus to their prostomial part. Fingerlings were exposed to different concentrations according to the Organization for Economic Co-operation and Development (OECD) standard method, to determine the $\mathrm{LC}_{50} 96 \mathrm{~h}$ of fingerlings. Number of dead fish was recorded at time $24,48,72$, and 96 h. $^{25}$

\section{Statistical analysis}

The vulnerability of the test species to the various test chemicals was determined using a computerized probit method of analysis according to Finney ${ }^{26}$ for the $\mathrm{LC}_{50}$ at day 4 and 14 respectively. In addition, the analysis of variance (ANOVA) in Statistical Package for Social Science (SPSS) statistical software in Version 15.0 was also used to test the variables at $\mathrm{P}<0.05$ level of significance.

\section{Results}

\section{Mortality and fish behaviour}

The toxicological endpoint used in this study was mortality. Mortality in the test tanks for each concentration was recorded at 24,48 , 72 and $96 \mathrm{~h}$ when the fish failed to show the evidence of opercula activity and do not respond to gentle prodding. The dead organ- isms were removed immediately. There was no death or physiological change in the control tanks throughout the $96 \mathrm{~h}$ test period. The influence of concentration, exposure duration and environmental conditions were observed in this study. Death rate increased with increase in concentration and exposure duration. Varying behavioural patterns observed in the fish include: erratic swimming, loss of reflexes, loss of equilibrium, paleness of skin and gasping for air.

The $96 \mathrm{~h}$ mean \% mortality recorded in the industrial test chemicals for four varying concentrations ranging between 1.25 and $200 \mathrm{mg} / \mathrm{l}$ are indicated as follows: Rigwash (57, 80, 100, $100 \%)$, Oil eater $(13,30,100,100 \%)$, Nalco EC1304A/COT $505(53,77,100,100 \%)$ and Glycol $^{\mathrm{TM}}(40,100,100,100 \%)$. In the pesticide test, values recorded for Propoxur was 0, 7, 27, $60 \%$ Atrazine (27.1, 36.7, 52.6, 100\%), Furadan $(47.53, \quad 49.29, \quad 50.32, \quad 78.70 \%) \quad$ while Deltamethrin was 30, 80, 100, 100\%. However, from the results obtained, the mean $\%$ mortality at $96 \mathrm{~h}$ exposure in the test chemicals and control groups was significantly different at $\mathrm{P}<0.05$.

The acute toxicity of the chemicals was also evaluated using estimated $96 \mathrm{~h} \mathrm{LC}_{50}$ values in varying concentrations. The estimated $96 \mathrm{~h}$ $\mathrm{LC}_{50}$ values for Rigwash, Oil eater, Nalco EC1304A/C0T 505, Glycol, Propoxur and
Deltamethrin were $26.34 \pm 0.46,6.02 \pm 0.30$, $3.07 \pm 0.14,1.31 \pm 0.01,20.91 \pm 0$ and $0.001 \pm 0$ $\mathrm{mg} / \mathrm{l}$ respectively. The estimated safe limits for these chemicals are $10 \%$ of the $96 \mathrm{~h} \mathrm{LC}_{50}$. The fish were sensitive to the test chemicals however; the control organisms were active and responded to stimuli throughout the experimental period.

Changes in behaviour were observed already after one hour of exposure to the industrial chemicals and pesticides in the groups of fish in the highest concentrations (250 and $500 \mathrm{mg} / \mathrm{l}$ for industrial chemicals and 10 and $15 \mathrm{mg} / \mathrm{l}$ for pesticides). The behavioural changes were also observed in the group exposed to $62.5 \mathrm{mg} / \mathrm{l}$ for industrial chemicals and $5 \mathrm{mg} / \mathrm{l}$ for pesticides after 24 hours, but these changes were not so intensive. Abnormal behaviour included reduced reflexes, erratic swimming, loss of equilibrium, and accelerated respiration. In the highest concentration, the fish were lying on their side and were moving only in this position. No changes in behaviour were observed in the control group and experimental group exposed to $2.5 \mathrm{mg} / \mathrm{l}$ of atrazine as well as in all groups during the recovery period.

\section{Toxicological effects to earthworms}

The test organisms exposed to the various test concentrations of the industrial chemicals

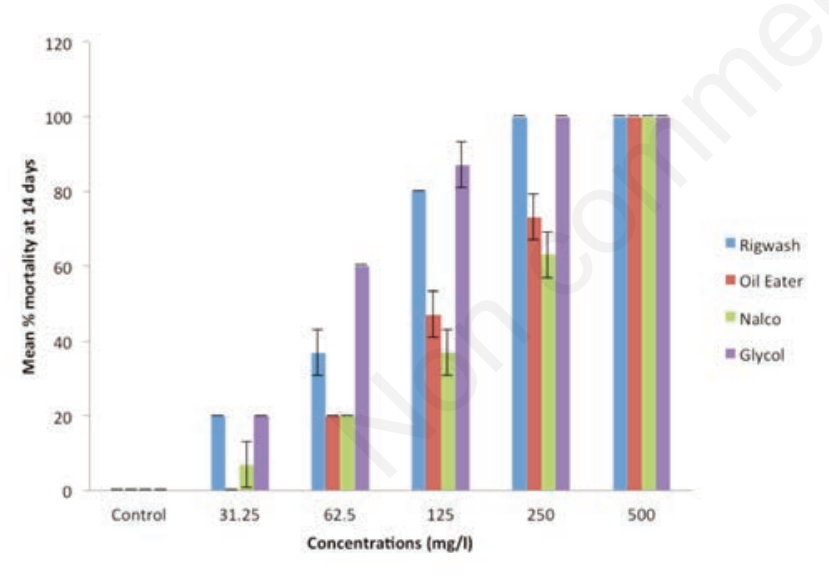

Figure 1. Mortality (mean \pm standard error) of earthworms following a 14-day exposure to industrial chemicals.

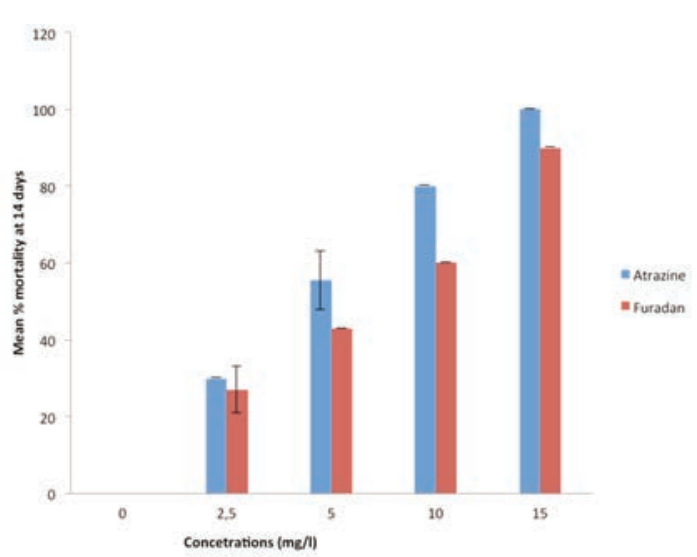

Figure 2. Mortality (mean \pm standard error) of earthworms following a 14-day exposure to pesticides.

Table 1. Acute toxicity profile of fish (Tilapia guineensis) exposed to the test chemicals at 96 hours.

\begin{tabular}{|c|c|c|c|c|c|c|}
\hline & Rigwash & Oil Eater & Nalco & Glycol & Propoxur & Deltamethrin \\
\hline 96 hour $\mathrm{LC}_{50}$ & $26.34 \pm 0.46$ & $6.02 \pm 0.30$ & $3.07 \pm 0.14$ & $1.31 \pm 0$ & $20.91 \pm 0$ & $0.001 \pm 0$ \\
\hline Safe limit & 2.63 & 0.62 & 0.31 & 0.13 & 2.09 & 0.0001 \\
\hline $95 \% \mathrm{CL}$ & $14.09-40.26$ & $4.27-8.34$ & $1.41-4.88$ & $0.25-2.04$ & $13.7-141.83$ & $0.001-0.0010$ \\
\hline Probit line equation & $\begin{array}{c}Y=1.664+2.348 \\
x \log (\text { conc })\end{array}$ & $\begin{array}{c}Y=1.737+4.180 \\
x \log (\text { conc })\end{array}$ & $\begin{array}{c}\mathrm{Y}=3.985+2.082 \\
\mathrm{x} \log (\text { conc })\end{array}$ & $\begin{array}{c}Y=4.690+2.677 \\
x \log (\text { conc })\end{array}$ & $\begin{array}{c}\mathrm{Y}=1.199+2.879 \\
\mathrm{x} \log (\mathrm{conc})\end{array}$ & $\begin{array}{c}Y=2.1861+5.788 \\
x \log (\text { conc })\end{array}$ \\
\hline Slope & 2.65 & 1.74 & 3.02 & 2.34 & 2.21 & 1.48 \\
\hline
\end{tabular}

Where $\mathrm{Y}=$ Probit, conc. $=\mathrm{mg} / ; \mathrm{CL}=$ confidence limit; $\mathrm{LC}_{50}=$ lethal concentration. 
$(62.5-500 \mathrm{mg} / \mathrm{kg})$ and pesticides $(2.5-15$ $\mathrm{mg} / \mathrm{kg}$ ) at test termination (day 14) are shown in the Figures 1 and 2 respectively. The observed results exhibited a clear concentration-dependent relationship, which indicated that worms exposed to the test chemicals had mean \% mortality that increased with increased concentration and exposure time for all industrial chemicals and pesticides tested. The mean mortality for the control experiment was significantly different from the results obtained for the test chemicals at levels of $\mathrm{P}<0.05$. The acute toxicity profile of the chemicals was also evaluated using estimated 14day $\mathrm{LC}_{50}$ values in varying concentrations. The estimated 14-day $\mathrm{LC}_{50}$ values for Rig wash, Oil eater, Nalco EC1304A/COT 505, Glycol, Atrazine, Furadan were $80.05 \pm 3.5$, $151.55 \pm 10.7,172.63 \pm 14.2,63.72 \pm 2.43,4.97 \pm 0$ and $0.29 \pm 0 \mathrm{mg} / \mathrm{kg}$ respectively (Table 2 ).

\section{Discussion}

Following exposure to the experimental organisms, the test chemicals resulted in mortality of the fish fingerlings when compared with the control, indicating an effect induced by the chemicals. Fish mortality increased with increased concentrations and exposure time. This study used laboratory test, which could be extrapolated to possible field concentration since the chemicals usually find their way into waters or land via indiscriminate disposal and unintentional release into the environment of the Nigeria Niger Delta. In Nigeria, atrazine for example is a common herbicide used in farmlands and to date there seems to be dearth of information regarding its effect on earthworms. The mortality values reported for Tilapia guineensis were influenced by toxicity modifying factors such as exposure duration, concentrations, type of chemicals and environmental conditions. The estimated $96 \mathrm{~h} \mathrm{LC}_{50}$ values obtained in this study compared with GESAMP rating showed that the test chemicals were toxic. ${ }^{27}$

Industrial chemicals (demulsifiers, dispersants, corrosion inhibitors) and their metabolites contain active ingredients which could be absorbed through respiratory membranes of aquatic organisms that can prevents the exchange of gases and ultimately leads to death. ${ }^{11}$ Most industrial chemicals and pesticides are persistent and bioaccumulative. This implies that they remain in the food chain, often absorbed in body fat where they can wreak havoc for a long time. However, the faster a given chemical or pesticide breaks down in the environment, the less threat it poses to aquatic life. ${ }^{28}$

Some pesticides that are applied to water to kill plants are toxic to fish and other water animals at concentrations similar to those used to kill the plants. ${ }^{29}$ As have been noted earlier, repeated exposure to sub-lethal doses of some pesticides can cause physiological and behavioural changes in fish that reduce populations, by causing abandonment of nests and broods, decreased immunity to disease and increased failure to avoid predators. ${ }^{29}$ Pesticides acted by blocking the organism's nervous system, causing malfunction, tremors, and death. Most of which are relatively insoluble, persist in soils and aquatic sediments, bioconcentrate in the tissues of invertebrates and vertebrates from their food, move up trophic chains, and affect top predators. ${ }^{30}$ The amount of pesticide that migrates from the intended application area is influenced by the particular chemical's properties such as its propensity for binding to soil, water solubility, and resistance to being broken down over time. ${ }^{31}$

The estimated $\mathrm{LC}_{50}$ obtained were quiet comparable with previous and related studies. Ezemonye et al. ${ }^{32}$ reported a range of 13.79 $20.41 \mathrm{mg} / \mathrm{l}$ for Neatex (industrial detergent) and 12.43 - $14.73 \mathrm{mg} / \mathrm{l}$ for Norust CR 486 (corrosion inhibitor) exposed to 14-day old Tilapia guineensis at 96 h. Similarly, Nwoko et al. ${ }^{33}$ reported an acute toxicity value of a corrosion inhibitor exposed to African catfish (Clarias Gariepinus) at $96 \mathrm{~h}$ as $0.228 \pm 0.007 \mathrm{mg} / \mathrm{l}$. Other studies which showed similar comparison include the research works by several other Authors. ${ }^{9-11,18,34-39}$

Soil organisms enhance soil aggregation and porosity, thus increasing infiltration and reducing runoff. Earthworms are an important component of the soil system, and can enhance plant growth by improving soil fertility and nutrient recycling. ${ }^{40}$ They are important for conditioning soil since they aerate and ingest soil and other organic matter as they tunnel. They break up thatch, a layer of dead matter that can accumulate on the soil surface and excrete material, called castings, which enrich the soil and provide many benefits to gardeners and farmers. They represent the greatest part of biomass of terrestrial invertebrates ( $>80 \%)$ and play an important role in soil ecosystem. They are used as bioindicator of soil contamination providing an early warning of decline in soil quality and serve as model organisms in toxicity testing. However, pesticides and fungicides used to control insects and fungus may pose a great threat to earthworms and harm them. This could reduce earthworm populations significantly, causes rigidity and immobility. ${ }^{41}$

Earthworms are characterized by high ability to cumulate a lot of pollutants from soil in their tissues, thus they are used for studying of toxicity potential of chemicals. The differential acute toxicity levels of the chemicals as shown in the $\mathrm{LC}_{50}$ values for the soil toxicity may be attributed to the toxic constituents of the chemicals. ${ }^{42}$ This is because organisms are known to react differently to varying stressors depending on their toxicity profile. There was high indication that the chemicals induced death in the test organisms due to the fact that there was significant difference between the test concentrations and the control groups. Soil contaminated with organic pollutants (e.g. dispersant, corrosion inhibitors, pesticides, detergents etc) can be detrimental to earthworm populations. In concentrations of 50-100 ppm surfactants would not only denature the cells proteins, but also totally inactivate the enzyme and actually alter the cell wall permeability. The hazardous effects of chemicals and pesticides on aquatic and terrestrial organisms have been reported by other Authors. ${ }^{43-45}$ Ezemonye et al. $^{43}$ reported a 14 -day $\mathrm{LC}_{50}$ value of 511.32 and $207.61 \mathrm{mg} / \mathrm{kg}$ for earthworms exposed to an industrial detergent and corrosion inhibitor respectively.

Many of the substances used in the formulation of these chemicals are persistent soil contaminants, whose impact may endure for decades and adversely affect soil conservation. Similarly, the use of pesticides decreases the general biodiversity in the soil. Not using the chemicals results in higher soil quality, thus

Table 2. Acute toxicity profile of earthworm (Aporrectodea longa) exposed to the test chemicals at day 14 .

\begin{tabular}{|c|c|c|c|c|c|c|}
\hline & Rigwash & Oil Eater & Nalco & Glycol & Propoxur & Deltamethrin \\
\hline 14 day $\mathrm{LC}_{50}$ & $80.05 \pm 3.5$ & $151.55 \pm 10.7$ & $172.63 \pm 14.2$ & $63.72 \pm 2.43$ & $4.97 \pm 0$ & $0.29 \pm 0$ \\
\hline Safe limits & 8.01 & 15.16 & 17.26 & 6.37 & 0.50 & 0.03 \\
\hline $95 \% \mathrm{CL}$ & $49.49-118.83$ & $94.18-230.13$ & $113.77-273.64$ & $35.02-95.98$ & $2.74-7.37$ & $0.14-0.54$ \\
\hline Probit line equation & $\begin{array}{c}Y=-0.045+2.650 \\
x \log (\text { conc })\end{array}$ & $\begin{array}{c}\mathrm{Y}=-1.117+2.807 \\
\mathrm{x} \log (\text { conc })\end{array}$ & $\begin{array}{c}Y=-0.892+2.634 \\
x \log (\text { conc })\end{array}$ & $\begin{array}{c}Y=0.514+2.486 \\
x \log (\text { conc })\end{array}$ & $\begin{array}{c}Y=3.119+2.702 \\
x \log (\text { conc })\end{array}$ & $\begin{array}{c}Y=6.143+2.123 \\
x \log (\text { conc })\end{array}$ \\
\hline Slope & 2.36 & 2.26 & 2.38 & 2.50 & 2.33 & 2.93 \\
\hline
\end{tabular}

Where $\mathrm{Y}=$ Probit, conc. $=\mathrm{mg} / \mathrm{l} ; \mathrm{CL}=$ confidence limit; $\mathrm{LC}_{50}=$ lethal concentration. 
the factors in the soil, such as its texture, its ability to retain water, and the amount of organic matter contained in it, also affect the amount of pesticide that would be degraded. With the additional effect that more organic matter in the soil allows for higher water retention. A smaller content of organic matter in the soil increases the amount of pesticide that will leave the area of application, because organic matter binds to and helps break down pesticides. ${ }^{46}$

Pesticides enter the soil via spray drift during foliage treatment, wash-off from treated foliage, release from granulates or from treated seeds in soil. Some pesticides such as soil fumigants and nematocides are applied directly into soil to control pests and plant diseases presented in soil. As earlier indicated, the transport, persistence or degradation of pesticides in soil depends on their chemical properties as well as physical, chemical and biological properties of the soil. These factors affect sorption/desorption, volatilisation, degradation, uptake by plants, run-off, and leaching of pesticides. ${ }^{47}$

\section{Conclusions}

In conclusion, the study showed that acute exposure of the test chemicals could cause death in fish and earthworms. Aquatic systems reflect perturbations in the environment; hence fish and invertebrates can often be used to indicate the health of an aquatic system because chemicals can accumulate in invertebrates from the water and sediment and in fish from water, sediment, and the food chain. The monitoring of these effects is extremely important to regulate and remediate pollution. It is believed that death caused to the organisms could lead to reduction or elimination of potentially reproductive species. Regulators set limits for the discharge of chemicals into the environment to ensure environmental sustainability of the ecosystem. Thus, safety factors are arbitrarily built in around the $96 \mathrm{~h} \mathrm{LC}_{50}$ values in order to arrive at environmentally tolerable concentrations. The safe concentration of a chemical in the receiving water body should not exceed $10 \%$ of the $96 \mathrm{~h} \mathrm{LC}_{50}$. The data from this study could be included in the material safety data sheet (MSDS) and the safe handling of chemical (SHOC) card, to enable the end users to take the necessary precautions for proper disposal. We need to manage the risk better by only using chemicals, which are safe since this would help ensure amongst others that the delicate biotic components of the rich Nigerian Niger Delta biodiversity are prudently protected.

\section{Research highlights}

- Ecotoxicological effects of industrial chemicals and pesticides on Tilapia guineensis (fish) and Aporrectodea longa (earthworms) should be monitored

- Adherence to standard safety limits/measures should be maintained during use and disposal of hazardous chemicals

- The biotic components of the Nigerian Niger Delta ecosystem should be prudently protected

\section{References}

1. Stuart S, Chanson J, Cox N, Young B, Rodrigues A, Fischman D, Waller R. Status and trends of amphibian declines and extinctions worldwide. Science 2004;306:1783-6.

2. Wake DB, Vredenburg VT. Are we in the midst of the sixth mass extinction? A view from the world of amphibians. Proc Natl Acad Sci U S A 2008;105:11466-73.

3. Ogbomida ET, Ezemonye LI. 2013. Elevation of testosterone level in periwinkle snail tympanotonus fuscatus var radula exposed to bis-tributyltin oxide (TBT0). Bioscientist 1:147-57.

4. Du Preez LH, Solomon KR, Carr JA, Giesy JP, Gross TS, Kendall RJ, et al. Population structure characterization of the clawed frog (Xenopus laevis) in corn-growing versus non-corn-growing areas in South Africa. Afr J Herpetol 2005;54:61-8.

5. Frampton GK, Dorne JLCM. The effects on terrestrial invertebrates of reducing pesticide inputs in arable crop edges: a metaanalysis. J Appl Ecol 2007;44:362-73.

6. Relyea RA, Hoverman JT. Interactive effects of predators and a pesticide on aquatic communities. Oikos 2008;117:1647-58.

7. Geiger F, Bengtsson J, Berendse F, Weisser WW, Emmerson M, Morales MB, et al. Persistent negative effects of pesticides on biodiversity and biological control potential on European farmland. Basic Appl Ecol 2010;11:97-105.

8. Ferencz L, Balog A. A pesticide survey in soil, water and foodstuffs from entral Romania. Carpathian J Earth Environ Sci 2010;5:111-8.

9. Ogeleka DF, Ezemonye LIN, Okieimen FE. Sublethal effects of industrial chemicals on fish fingerlings (Tilapia Guineensis). Afr J Biotechnol 2010;9:1839-43.

10. Ogeleka DF, Ezemonye LIN, Okieimen FE. Toxicity of industrial chemicals on biological indicators in water, sediment and soil. Int Res J Biotechnol 2010;1:37-43.

11. Abel PD. Toxicity of synthetic detergents to fish and aquatic invertebrates. J Fish Biol
2006;6:279-98.

12. Miller GT. Sustaining the Earth, $6^{\text {th }}$ ed. Vol. 9. Pacific Grove, CA: Thompson learning, Inc.; 2004. pp 211-216.

13. Anasco N, Uno S, Koyama J, Matsuoka T, Kuwahara N. Assessment of pesticide residues in freshwater areas affected by rice paddy effluents in Southern Japan. Environ Monitor Assess 2010;160:371-83.

14. Fantke P, Friedrich R, Jolliet 0 . Health impact and damage cost assessment of pesticides in Europe. Environ Int 2012;49:9-17.

15. Adamski Z, Machalska K, Chorostkowska K, Niewadzi M, Ziemnicki K, Hirsch HVB. Effects of sublethal concentrations of fenitrothion on beet armyworm (Lepidoptera: Noctuidae) development and reproduction. Pest Biochem Physiol 2009;94:73-8.

16. Federal Environmental Protection Agency (FEPA). Guidelines and standards for environmental pollution control in Nigeria; 1991. pp 238-245.

17. Department of Petroleum Resources (DPR). Environment guidelines and standards for the petroleum industry in Nigeria (EGASPIN) - Revised Edition; 2002.

18. Ezemonye LIN, Ogeleka DF, Okieimen FE. Biological alterations in fish fingerlings (Tilapia guineensis) exposed to industrial detergent and corrosion inhibitor. Chem Ecol 2007;23:1-10.

19. Ezemonye L, Tongo I. Sublethal effects of endosulfan and diazinon pesticides on glutathione-S-transferase (GST) in various tissues of adult amphibians (Bufo regularis). Chemosphere 2010;8:214-7.

20. Organisation for Economic Co-operation and Development (OECD). "Fish, Acute Toxicity Test” OECD Guideline for Testing Chemicals 203. Paris: OECD; 1992. pp 1-9.

21. OECD. OECD Guideline for Testing of Chemicals, No. 207, Earthworm Acute Toxicity. Paris: OECD; 1984.

22. OECD. OECD Guideline for Testing of Chemicals, No. 222, Earthworm Reproduction Test (Eisenia fetida/Eisenia andrei). Paris: OECD; 2004.

23. ISO. ISO 1993:11268-1 - Soil-qualityeffects of Pollutants on Earthworms (Eisenia fetida). Part 1 Determination of Acute Toxicity using Artificial Soil Substrate. Geneva: International Standardization Organization; 1993.

24. Sandoval MC, Veiga M, Hinton J, Klein B. Review of biological indicators for metal mining effluents: a proposed protocol using earthworms. Proc. 25th Annual British Columbia Reclamation Symposium; 2001. pp 67-79.

25. Organisation for Economic Co-operation and Development (OECD). "Earthworm, acute toxicity test" OECD guideline for 
testing chemicals 207. Paris: OECD; 1984. pp 1-9.

26. Finney DJ. Probit analysis. Third edition. Cambridge: Cambridge University Press; 1971.

27. Group of Experts on the Scientific Aspects of Marine Environmental Protection (GESAMP). (IMO/FAO/UNESCO-OC/WMO /WHO/IAEA/UN/UNEP). Joint Group of Experts on the Scientific Aspects of Marine Environmental Protection). Towards safe and effective use of chemicals in coastal aquaculture. Reports and Studies, GESAMP. No. 65. Rome: FA0; 1997.

28. Bocquene G, Franco A. Pesticide contamination of the coastline of Martinique. Marine Pollut Bull 2005;51:612-9.

29. Helfrich LA, Weigmann DL, Hipkins P, Stinson ER. Pesticides and aquatic animals: a guide to reducing impacts on aquatic systems. Virginia Cooperative Extension; 1996.

30. Beketov M, Liess M. Potential of 11 pesticides to initiate downstream drift of stream macroinvertebrates. Archiv Environ Contamin Toxicol 2008;55:247-53.

31. Coat S, Bocquene G, Godard E. Contamination of some aquatic species with the organochlorine pesticide chlordecone in Martinique. Aquat Living Resour 2006;19:181-7.

32. Ezemonye LIN, Ogeleka DF, Okieimen FE. Lethal toxicity of industrial chemicals to early life stages of Tilapia Guineensis. J Hazard Mater 2008;157:64-8.
33. Nwoko CN, Ogeleka DF, Okieimen FE, Okonedo JOO. Acute toxicity of corrosion inhibitor to African catfish (Clarias Gariepinus). Nig J Appl Sci 2007;25:69-72.

34. Bury NR, McGeer JC, Wood CM. Effects of altering freshwater Chemistry on physiological responses of rainbow trout to silver exposure. Environ Toxicol Chem 1999;18: 49-55.

35. George A, Clark JR. Acute toxicity of two corexit dispersants. Chemosphere 2000;40:897-906.

36. Chindah AC, Sikoki FD, Vincent-Akpu, Ijeoma. Toxicity of an organophosphate pesticide (chloropyrifos) on a common Niger Delta Wetland fish - Tilapia guineensis (Blecker 1862). J Appl Sci Environ Manage 2004;8:11-7.

37. Scarlett A, Galloway TC, Canty M, Smith EL, Nilsson J. Comparative toxicity of two oil dispersants, superdispersants - 25 and corexit 9527, to a range of coastal species. Environ Toxicol Chemist 2005;15:1219-27.

38. Johnson TA, Miller LM, Whittle DM, Brown SB, Wieg DM, Kapuscinnsk AR, Leggett WC. Effects of materially transferred organochlorine contaminants of early life survival in a fresh-water fish. Environ Toxicol Chemist 2005;24:2594-602.

39. Gilliom RJ. Pesticides in U.S. streams and groundwater. Environ Sci Technol 2007;41: 3408-14.

40. Lee KE. Earthworms: their ecology and relationships with soils and land use. Sydney: CSIR0; 1985.

41. Downing HF, DeLorenzo ME, Fulton MH,
Scott GI, Madden CJ, Kucklick JR. Effects of the agricultural pesticides atrazine, chlorothalonil, and endosulfan on South Florida microbial assemblages. Ecotoxicology 2004;13:245-60.

42. Edwards CA, Bohlen PJ. The effects of toxic chemicals on earthworms. Rev Environ Contam Toxicol Earthworms 1992;373:2399.

43. Ezemonye LIN, Ogeleka DF, Okieimen FE. Toxicity of Neatex (industrial detergent) and Norust CR 486 (corrosion inhibitors) to earthworms (Aporrectodea longa) in naturally spiked soil. Afr J Biotechnol 2006;5:1113-7.

44. Konstantinou IK, Hela DG, Albanis TA. The status of pesticide pollution in surface waters (rivers and lakes) of Greece. Part I. Review on occurrence and levels. Environ Pollut 2006;141:555-70.

45. Amalin DM, Pena JE, Duncan R, Leavengood J, Koptur S. Effects of pesticides on the arthropod community in the agricultural areas near the Everglades National Park. Proceedings of the Florida State Horticultural Society; 2009.

46. Johnston AE. "Soil organic-matter, effects on soils and crops". Soil Use Manage 1986;2:97-105.

47. de Jong FMW, de Snoo GR, van de Zande JC. Estimated nationwide effects of pesticide spray drift on terrestrial habitats in the Netherlands. J Environ Manage 2008;86:721-30. 